\title{
NOTE
}

\section{Application of a Marker Dye on Sephadex LH-20 Column Chromatography in Radioimmuno-Assay of Plasma Aldosterone}

\author{
SHUICHI ICHIKAWA, KAZUHIKo MURATA AND RyoICHI SHIGIYA \\ 2nd Department of Internal Medicine \\ Gunma University School of Medicine, Maebashi 371
}

\begin{abstract}
Synopsis
Aldosterone in $2 \mathrm{ml}$ of plasma was determined by radioimmunoassay. A small modified $10 \mathrm{~m} l$ pipette column of LH-20 $(0.8 \times 15 \mathrm{~cm})$ was used for separation and 1,4diaminoanthraquinone was employed as a marker dye. The application of the small modified column and the marker dye made the separation easy, rapid and accurate. The recovery, precision, accuracy, sensitivity and specificity of the method were satisfactory. This method was considered to be convenient enough for clinical use.
\end{abstract}

Although various methods have been reported by many authors for radioimmunoassay of plasma aldosterone (Ito et al., 1972; Gomez-Sanchz et al., 1973; Farmer et al., 1973), the previous methods require complicated procedures and a long time for extraction and separation. In order to establish a rapid, easy and accurate method for plasma aldosterone radioimmunoassay, we have attempted an application of 1,4-diaminoanthraquinone as a marker dye and a relatively short Sephadex LH-20 column of $0.8 \times$ $15 \mathrm{~cm}$ for separation of aldosterone. The following is the brief description of our whole procedure.

\section{Materials and Methods}

D-aldosterone-1, 2- $\mathrm{H}^{3}(54 \mathrm{Ci} / \mathrm{mM})$, corticosterone$4-\mathrm{C}^{14} \quad(57.3 \mathrm{mCi} / \mathrm{mM})$, cortisone-4-C $\mathrm{C}^{14} \quad(59.8 \mathrm{mCi} /$ $\mathrm{mM})$ and cortisol-4- $\mathrm{C}^{14}(55.1 \mathrm{mCi} / \mathrm{mM})$ were obtained from New England Nuclear Corp., Boston and/or from the Radiochemical Center, Amersham. Unlabeled aldosterone, deoxycorticosterone, corticosterone, cortisol and cortisone were purchased from Sigma Chemical Co., St. Louis. Other materials were

Received for publication May 27, 1974.
Sephadex LH-20, Dextran T 70 (Pharmacia, Uppsala), Norit A (Wako Pure Chemical Industries, Osaka), bovine serum albumin (BSA) (Armour, Fraction V) and 1,4-diaminoanthraquinone (Tokyo Chemical Industry Co., Tokyo).

Solvents (GR grade) were used without further purification.

All glass ware was rinsed with methanol just before use.

Antialdosterone serum (NIH Lot \#088) was kindly supplied from National Institute of Arthritis and Metabolic Diseases, NIH, Bethesda, U.S.A.

\section{Extraction and Separation of Plasma Aldosterone}

Figure 1 shows the procedure for extraction and separation of aldosterone. Two $\mathrm{m} l$ of plasma, 1,000 $\mathrm{cpm}$ of $\mathrm{H}^{3}$-aldosterone and $100 \mu l$ of $0.1 N \mathrm{NaOH}$ were added to $20 \mathrm{~m} l$ of dichloromethane. After mixing for $1 \mathrm{~min}$. on a Vortex type mixer, the dichloromethane fraction containing aldosterone was transfered to a glass tube. The fraction was dried down, and then the separation of aldosterone was performed using a Sephadex LH-20 column $(0.8 \times 15 \mathrm{~cm})$. A $10 \mathrm{ml}$ pipette has been modified as a column shown in Fig. 2. Sephadex $\mathbf{L H}-20$ was prepared in $\mathrm{CH}_{2} \mathrm{Cl}_{2}(98)$ : $\mathrm{CH}_{3} \mathrm{OH}(2)$. The dried sample was introduced into the column and washed with $0.1 \mathrm{~m} l \times 2$ of the mobile solvent with 1,4-diaminoanthraquinone as a marker dye. The marker dye concentration was not more than $0.01 \%$.

The elution of aldosterone was started, when the marker dye reached $1.5 \mathrm{ml}$ on the scale of the column. The following $4 \mathrm{~m} l$ of eluate was collected. The 
Plasma $(1-2 \mathrm{~m} /)$

Add $1,000 \mathrm{cpm}$ of $\mathrm{H}^{3}$-Aldosterone Add $100 \mu l$ of $0.1 N \mathrm{NaOH}$

Extract with dichloromethane $(20 \mathrm{ml})$

Column chromatography

Sephadex LH-20 $(0.8 \times 15 \mathrm{~cm})$

Eluate with dichloromethane (98): methanol (2)

dry down and redissolved in $1.7 \mathrm{ml}$ of $1 \% \mathrm{BSA}$ in borate buffer ( $\mathrm{pH} 8.0)$

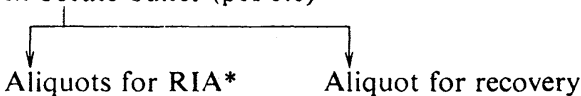

*RIA : Radioimmunøassay

Fig. 1. Procedure for extraction and separation of aldosterone.

eluate was dried down and redissolved in $1.7 \mathrm{ml}$ of borate buffer $(0.13 \mathrm{M}, \mathrm{pH} 8.0)$ containing $1 \% \mathrm{BSA}$.

\section{Assay Procedure}

One half $\mathrm{m} l$ of the sample was employed for recovery test, and $0.5 \mathrm{ml}$ of the sample was employed for assay in duplicate. One hundred microliter of appropriately diluted antiserum and $100 \mu l$ of borate buffer BSA containing $10,000 \mathrm{cpm} \mathrm{H}^{3}$-aldosterone were added to each sample and standard tube.

The contents were agitated on a Vortex type mixer and incubated at $4^{\circ} \mathrm{C}$ for $24 \mathrm{hrs}$. The free aldosterone was removed from the bound aldosterone by adding $1 \mathrm{~m} l$ of dextran coated charcoal suspension $(0.25 \%$ Dextran T 70 and $0.25 \%$ Norit A). The mixture was centrifuged at 3,000 r.p.m. for 10 minutes and the supernatant was transfered to a counting vial and mixed for 20 seconds with $10 \mathrm{ml}$ of liquid scintillation cocktail (100 mg POPOP, $4 \mathrm{~g}$ PPO in $1,000 \mathrm{~m} l$ toluen). The radioactivity of the sample was counted in a liquid scintillation spectrometer (Beckman, model LS-200B). Aldosterone concentration in the sample was calculated from the standard curve (Fig. 4).

\section{Results}

\section{Efficiency of Extraction}

The mean recovery of the added radioactivity was $77.8 \pm 8.9(\mathrm{SD}) \%(\mathrm{~N}=77)$.

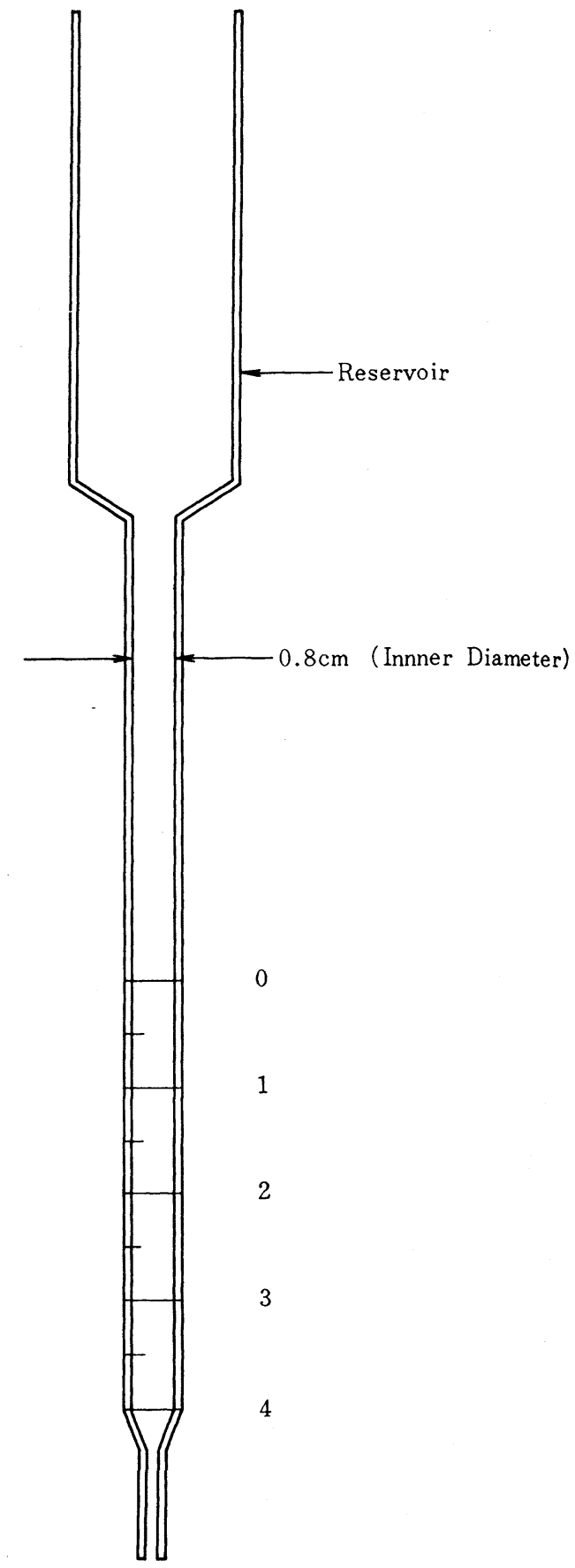

Fig. 2. Modified $10 \mathrm{~m} l$ pipette column. 


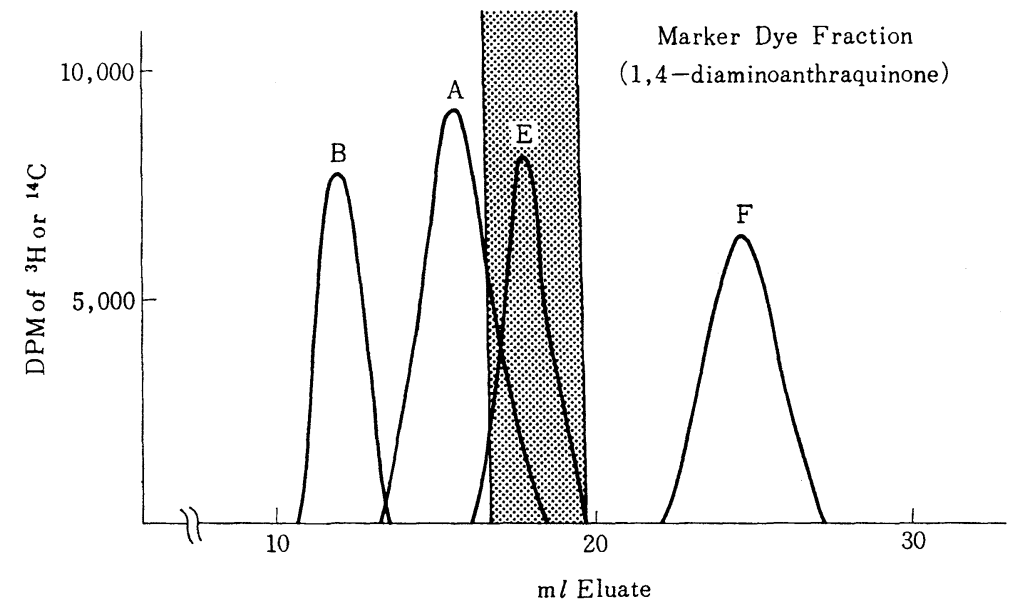

Fig. 3. Eluation pattern of aldosterone, corticosterone, cortisone and cortisol on Sephadex LH-20 column $(0.8 \times 15 \mathrm{~cm})$ with $\mathrm{CH}_{2} \mathrm{Cl}_{2}(98): \mathrm{CH}_{3} \mathrm{OH}(2)$

A: aldosterone

B: corticosterone

E: cortisone

F: cortisol

The shaded area shows the marker dye fraction.

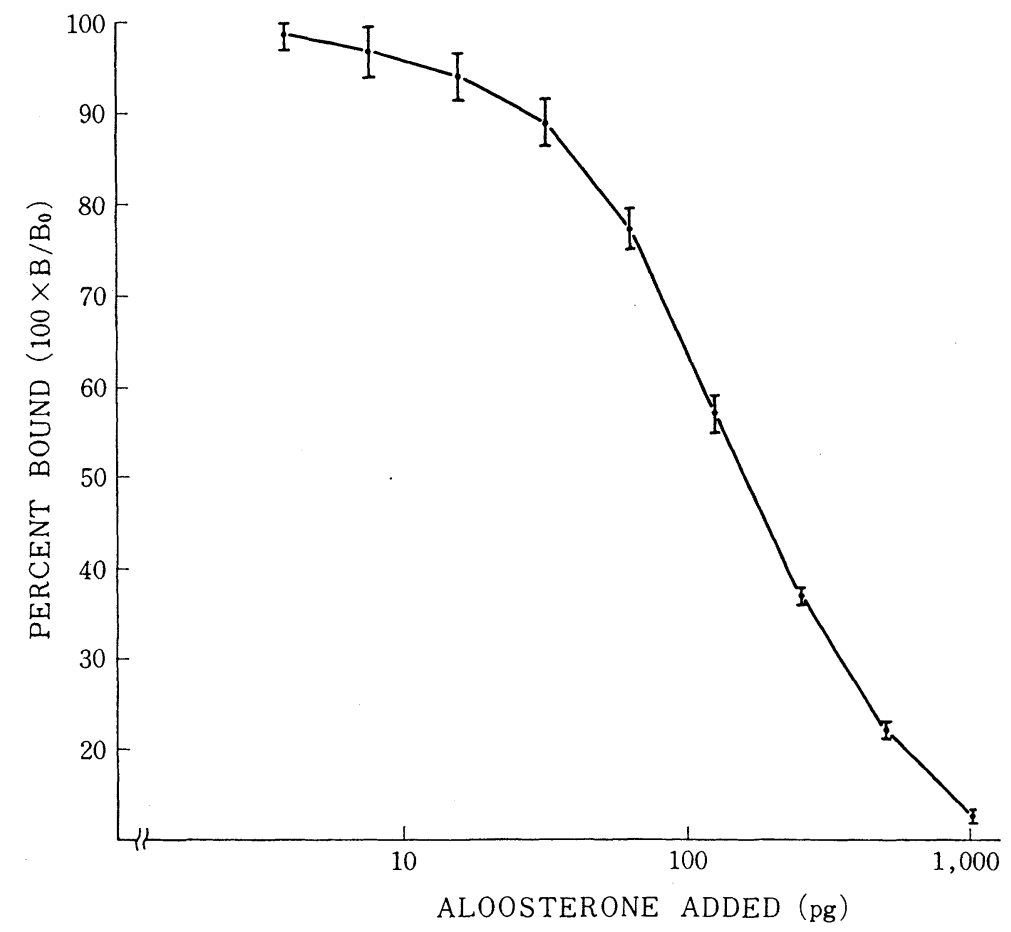

Fig. 4. Standard curve for aldosterone radioimmunoassay

$B$ : the number of cpm bound with unlabeled aldosterone

$\mathrm{B}_{0}$ : the number of $\mathrm{cpm}$ bound without unlabeled aldosterone $\mathrm{B}_{0} /$ Total $\times 100=40$ $\sim 50 \%$

Each point and bar indicate the mean value and standard deviation of 5 assays. 


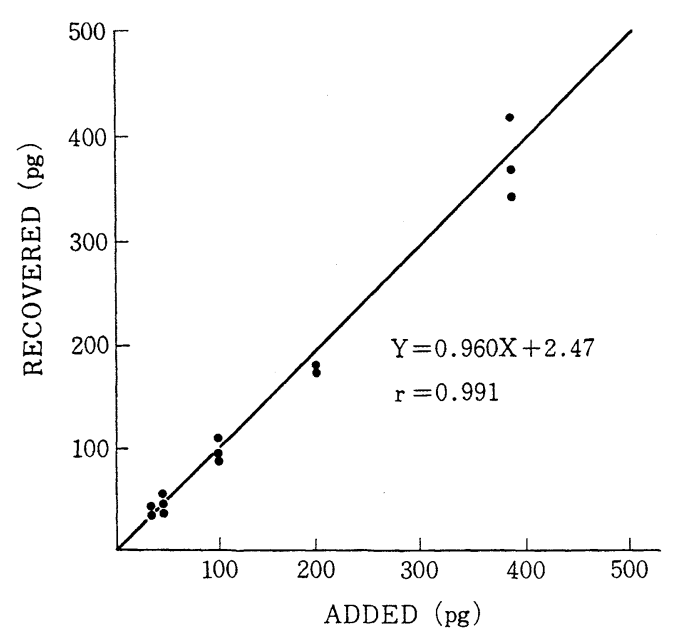

Fig. 5. Study of accuracy.

\section{Accuracy}

Known amounts of aldosterone were added to $2 \mathrm{~m} l$ of adrenalectomized or pooled plasma. The recovery of added hormone by substracting the blank value from the total amounts found was calculated. It was represented by the equation $\mathrm{Y}=0.960 \mathrm{X}+$ 2.47 (Fig. 5).

\section{Precision}

The precision of the method was estimated by repeated determination of aldosterone concentration in the same (intra-assay) and in different assays (inter-assay).

The coefficient of variation is $5.8 \%$ and $12.8 \%$, respectively.

\section{Method Blank and Adrenalectomized Plasma}

The values of water $(2 \mathrm{ml})$ and adrenalectomized plasma $(2 \mathrm{~m} l)$ were not significantly different from zero. Cortisone (40 ng), cortisol $(200 \mathrm{ng})$ and corticosterone $(80 \mathrm{ng})$ were added simultaneously to $2 \mathrm{~m} l$ of pooled plasma (aldosterone concentration $150 \mathrm{pg}$ ). The aldosterone value obtained was not affected by these steroids.

\section{Specificity}

We studied the cross-reaction of four
Table 1. Plasma aldosterone level in normal cases

\begin{tabular}{ccc}
\hline Case No. & $\begin{array}{c}\text { Recumbent } \\
(\mathrm{pg} / \mathrm{m} l)\end{array}$ & $\begin{array}{c}\text { After standing } \\
\text { for 2 hours } \\
(\mathrm{pg} / \mathrm{m} l)\end{array}$ \\
\hline 1 & 64.0 & 88.0 \\
2 & 113.0 & 136.0 \\
3 & 57.5 & 85.8 \\
4 & 77.8 & 115.4 \\
5 & 100.0 & \\
6 & 31.0 & \\
7 & 67.1 & \\
8 & 63.0 & $106.2 \pm 20.6$ \\
\hline Mean \pm SD & $81.8 \pm 21.5$ & \\
\hline
\end{tabular}

steroids; cortisone, corticosterone, cortisol and deoxycorticosterone according to the method described by Abraham (1969). The percent cross-reactions of cortisol, corticosterone, cortisone and deoxy corticosterone were 0.01 , $0.1,0.046$ and 0.025 , respectively.

\section{Plasma Aldosterone Concentration in Normals and Patients}

Eight normal individuals ( 3 women and 5 men on a normal sodium diet and keeping recumbent) had plasma aldosterone levels of $81.8 \pm 21.5 \mathrm{pg} / \mathrm{ml}$ (Mean $\pm \mathrm{SD})$. After standing for at least $2 \mathrm{hrs}$, four of these had 106.2 \pm $20.6 \mathrm{pg} / \mathrm{ml}$ (Table 2).

Two patients of primary aldosteronism showed high values of $1,389 \mathrm{pg} / \mathrm{ml}$ and $304 \mathrm{pg} / \mathrm{ml}$, respectively. One uremic patient showed $755 \mathrm{pg} / \mathrm{ml}$ of aldosterone.

\section{Discussion}

The separation procedure for plasma aldosterone described above is rapid, easy and accurate. It is suitable for clinical use. By using 1,4-diaminoanthraquinone as a marker dye and the Sephadex LH-20 column which was made by a modified $10 \mathrm{ml}$ pipette, we simplified the separation procedure and spared the time for separation. A shorter column than used before was applicable for 
the separation of aldosterone.

Although a marker dye is widely used for the separation of estrogen, an application of the dye as a marker has not as yet attempted for the separation of aldosterone using column chromatography. The assayed sample prepared contained only a very small amount of marker dye. The antigen-antibody reaction was not interfered with by the application of the dye. Ito et al. (1972) used Sephadex LH20 column $(1 \times 60 \mathrm{~cm})$ without a marker dye. Aldosterone can be well separated from other steroids by their column, which is too long to be handled for clinical use. The separation of aldosterone was sufficient enough for radioimmunoassay by our method. The precision, accuracy, sensitivity and specificity of the present method were satisfactory. The high specificity of the NIH antiserum (Lot $\# 088$ ) has been also reported by Hagiwara et al. (1973). The presence of other steroids did not interfere with the determination of plasma aldosterone levels as far as when the NIH antiserum was used.

The plasma aldosterone levels in the normal subjects in the present study were in good agreement with the values reported by other investigators using more complicated and time-consuming methods for the extraction and separation (Bayard et al., 1970; Mays et al., 1970; Farmer et al., 1973).

\section{Acknowledgement}

The authors are grateful to Dr. Takikawa for his kind advice. The antialdosterone serum was kindly supplied from National Institute of Arthritis and Metabolic Diseases, Bethesda, U.S.A. The authors also express their thanks to Dr. K. Wakabayashi for critical reviewing the manuscript.

\section{References}

Abraham, G. E. (1969). J. Clin. Endocr. 29, 866.

Bayard, F., I. Z. Beitins, A. Kowarski and C. J. Migeon (1970). J. Clin. Endocr. 31, 1. Farmer, R. W., D. H. Brown, P. Y. Howard and L. F. Farbre, Jr. (1973). J. Clin. Endocr. 36, 460 .

Gomez-Sanchez, C., D. C. Kem and N. M. Kaplan (1973). J. Clin. Endocr. 36, 795. Hagiwara, T., T. Yamamoto and Y. Kumahara (1973). Folia Endocrinol. Japon. 49, 619 (In Japanese).

Ito T., J. Woo, R. Haning and R. Horton (1972). J. Clin. Endocr. 34, 106.

Mays D., S. Furuyama, D. C. Kem and C. A. Nugent (1970). J. Clin. Endocr. 30, 682. 